\title{
Resonance Raman Study on Carbon Nanotubes Formation
}

\author{
A. Steplewska and E. Borowiak-Palen* \\ Centre of Knowledge Based Nanomaterials and Technologies, Institute of Chemical Engineering and Chemical \\ Technology, Szczecin University of Technology, Pułaskiego 10, 70-322 Szczecin, Poland
}

\begin{abstract}
Carbon nanotubes can be obtained from variety of the molecular precursors in chemical vapor deposition processes. The low growth temperatures strongly increase the compatibility of carbon nanotubes growth with current complementary metal-oxide-silicon technology for carbon nanotubes-based electronics. Here, we show the low temperature growth of multiwalled carbon nanotubes in acetylene chemical vapor deposition with $\mathrm{Fe}-\mathrm{Co} / \mathrm{MgO}$. The catalyst mix was active already at $450^{\circ} \mathrm{C}$. The higher temperatures growth $\left(500^{\circ} \mathrm{C}\right.$ and $\left.550^{\circ} \mathrm{C}\right)$ were also tested in order to estimate the best thermal condition in respect of the sample quality (via thermogravimetric analyzer) and the sample relative purity (via resonance Raman spectroscopy). High resolution transmission electron microscope was used to determine the morphology of the samples.
\end{abstract}

PACS numbers: 61.46.Fg, 61.46.Np, 81.07.De, 78.30.--j, 61.46.+w

\section{Introduction}

Carbon nanotubes (CNTs) were first described by Iijima [1] and since their discovery, they have contributed to the development of studies in the field of physics, chemistry and material sciences.

The carbon nanotubes have a great range of promising properties (e.g. mechanical and electronic properties $[2-4]$ ) and therefore, they are under investigation for a wide range of practical nanotechnology applications. Since their discovery, many methods of carbon nanotubes synthesis have been explored including electric arc-discharge [5], laser evaporation [6], chemical vapour deposition (CVD) [7, 8], and plasma-enhanced CVD (PECVD) [9]. CVD seems to be the most promising method for possible industrial scale-up due to the relatively low growth temperature, high yields and high purities that can be achieved. CVD can produce both multi- and single-wall carbon nanotubes (MWCNTs and SWCNTs) $[10,11]$.

For CNT-based electronics, PECVD has been explored for synthesis of nanotubes at lower temperatures $\left(450^{\circ} \mathrm{C}\right.$, $\left.500^{\circ} \mathrm{C}\right)[12-15]$.

This contribution presents CVD synthesis of CNTs in vacuum conditions at low pressure, with acetylene $\left(\mathrm{C}_{2} \mathrm{H}_{2}\right)$ as a carbon feedstock. The temperature of the experiments was set up from $405^{\circ} \mathrm{C}$ to $550^{\circ} \mathrm{C}$. Firstly, thermogravimetric analysis (TGA) of the catalyst $(\mathrm{Fe}-\mathrm{Co} / \mathrm{MgO})$ was measured. Differential thermal analysis (DTA) of it indicated that the catalyst maybe active already at $405^{\circ} \mathrm{C}$ therefore the first CVD process has been conducted at these thermal conditions. Next, the morphology, quality and purity of the samples were estimated using high resolution transmission electron microscope (HR-TEM), TGA/DTA, Raman spectroscopy, respectively.

* corresponding author; e-mail: eborowiak@zut.edu.pl

\section{Experimental}

The catalyst mix was prepared with a mixture of butanol $\mathrm{C}_{4} \mathrm{H}_{9} \mathrm{OH}$, cobalt acetate $\left(\mathrm{CH}_{3} \mathrm{CO}_{2}\right)_{2} \mathrm{Co} \cdot \mathrm{H}_{2} \mathrm{O}$, iron acetate $\left(\mathrm{CH}_{3} \mathrm{CO}_{2}\right)_{2} \mathrm{Fe}$ and magnesium oxide $\mathrm{MgO}$. The molar ratio of $\mathrm{Co}$ and $\mathrm{Fe}$ to $\mathrm{MgO}$ was 1:1:100. The detailed description of the preparation is presented elsewhere [16].

$15 \mathrm{mg}$ of the catalyst powder was placed into a ceramic crucible. Next, it was introduced to the thermogravimetric analyzer, evacuated $\left(\approx 10^{-2} \mathrm{mbar}\right)$ and then heated up to the temperature of $850^{\circ} \mathrm{C}$ with the temperature ramp $10^{\circ} \mathrm{C} / \mathrm{min}$. This experiment was performed to observe the mass change of the catalyst mix upon heating and find the minimal temperature of the active catalyst with a thermoweight TA Instruments DTA-Q600 SDT.

As prepared catalyst mix was introduced to the horizontal oven and was first evacuated $\left(\approx 10^{-3}\right.$ mbar $)$, then heated. After reaching the desired temperature $\left(405^{\circ} \mathrm{C}\right.$, $\left.450^{\circ} \mathrm{C}, 500^{\circ} \mathrm{C}, 550^{\circ} \mathrm{C}\right)$ acetylene vapours $(60 \mathrm{mbar})$ were introduced to the reactor. The dual time of each experiment was set up to $30 \mathrm{~min}$. After the processes the products were cooled down to the room temperature. The morphological studies of the received samples were conducted on a HRTEM - FEI Tecnai F20 (200 kV). Raman measurements were obtained using excitation laser lines $785 \mathrm{~nm}(1.58 \mathrm{eV})$ with a Renishaw InVia Raman Microscope spectrometer. The produced materials were incinerated in thermogravimetric oven until $850^{\circ} \mathrm{C}$ in order to determine the relative purity of the samples. Thermogravimetric measurements were performed with a thermoweight TA Instruments DTA-Q600 SDT.

\section{Results and discussion}

The curve of DTA analysis of the catalyst mix is presented in Fig. 1. The catalyst does not undergo mass changes above the temperature of $405^{\circ} \mathrm{C}$. Therefore, this temperature was chosen for the first CVD experiment. 


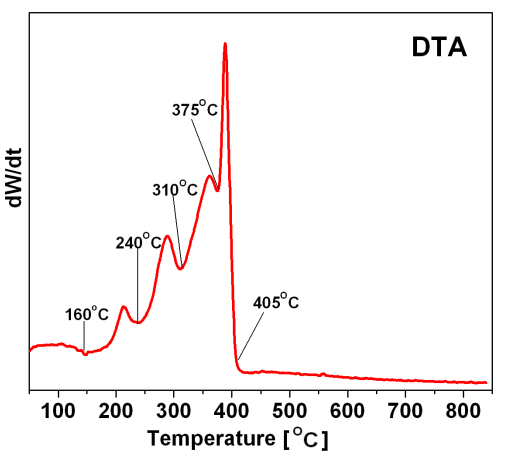

Fig. 1. The curves presenting DTA of catalyst $\mathrm{Fe}: \mathrm{Co} / \mathrm{MgO}(1: 1 / 100)$.

Four experiments have been performed at $405^{\circ} \mathrm{C}$, $450^{\circ} \mathrm{C}, 500^{\circ} \mathrm{C}, 550^{\circ} \mathrm{C}$ and the observations of their morphologies with TEM have been carried out (Fig. 2). The TEM analysis revealed that $405^{\circ} \mathrm{C}$ was too low to obtain CNTs and the sample contained only a mixture of amorphous carbon and graphitic nanoparticles. The next thermal condition was set up to $450^{\circ} \mathrm{C}$ and the TEM micrographs show the abundance of the nanotubes. The same effects were observed in case of sample prepared at the $500^{\circ} \mathrm{C}$ and $550^{\circ} \mathrm{C}$. This indicates that the lowest temperature to activate the catalysts for nanotubes lies between $405^{\circ} \mathrm{C}$ and $450^{\circ} \mathrm{C}$. To optimize the exact temperature for the CNTs formation more experimental studies should be conducted.

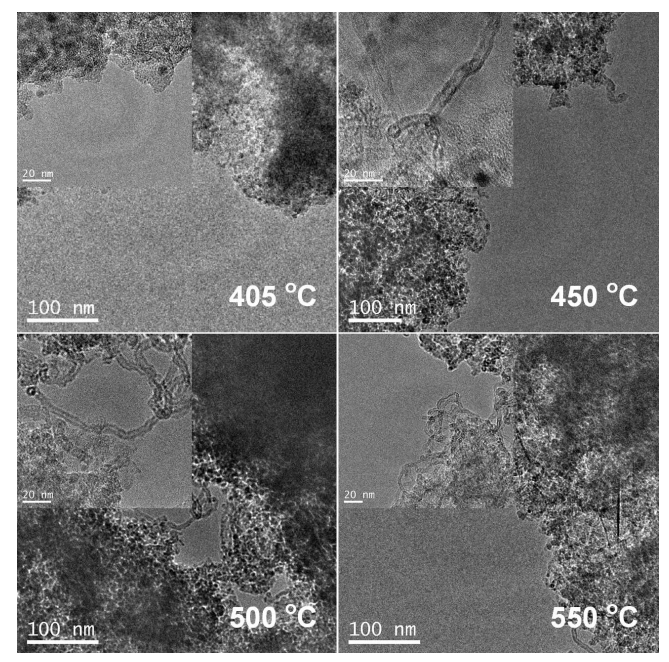

Fig. 2. TEM images of the materials synthesized at: $405^{\circ} \mathrm{C}, 450^{\circ} \mathrm{C}, 500^{\circ} \mathrm{C}$ and $550^{\circ} \mathrm{C}$. The process temperatures are indicated in the respective image.

More accurate analysis of TEM images led to the estimation of the diameter distributions of the samples (see Fig. 3). The outer diameters of the tubes were estimated between $1.5 \mathrm{~nm}$ and $11 \mathrm{~nm}$. The values for the samples are between $3-10 \mathrm{~nm}$ (for $450^{\circ} \mathrm{C}$ ), 2.5-11 nm (for $500^{\circ} \mathrm{C}$ ) and $1.5-11.5 \mathrm{~nm}\left(\right.$ for $550^{\circ} \mathrm{C}$ ). For all these ex- periments the values of the outer diameter distributions are surprisingly low in respect of the sample prepared at $850^{\circ} \mathrm{C}$. The outer diameter distribution of the material synthesized at $850^{\circ} \mathrm{C}$ is from $4 \mathrm{~nm}$ until $30 \mathrm{~nm}$. The histogram of the outer diameter distribution of the sample produced at $850^{\circ} \mathrm{C}$ and its typical TEM image are presented in the lower part of Fig. 3 (right side). This clearly suggests that the lowering of the process temperature reduces the diameter distribution of the tubes in the bulk material. In the presented cases the diameter distribution is reduced.

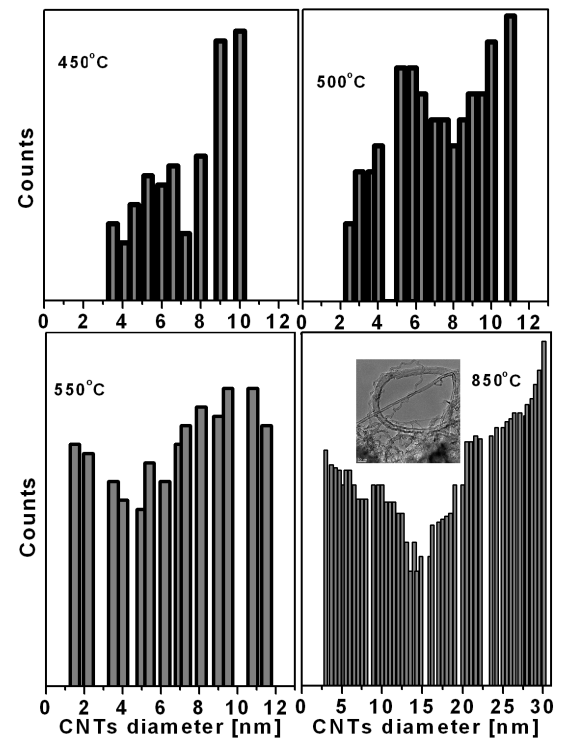

Fig. 3. The outer diameter distributions of the CNTs synthesized at $450^{\circ} \mathrm{C}, 500^{\circ} \mathrm{C}, 550^{\circ} \mathrm{C}$ and $850^{\circ} \mathrm{C}$ (inset: TEM image of CNTs synthesized at $850^{\circ} \mathrm{C}$ ).

In the next step Raman spectra of the samples were measured. The Raman spectra (Fig. 4A) for those samples, reveal strong bands at $1331 \mathrm{~cm}^{-1}$ and $1581 \mathrm{~cm}^{-1}$ corresponding to the D (disorder band) and G (graphite mode) lines typical for carbon nanotubes. The ratio of the intensity of the D and G bands is usually used as a direct measure of the quality of the sample. Figure $4 \mathrm{~B}$ presents the ratios of $G / D$ modes intensities versus the synthesis temperature.

The increase of the process temperature up to $500^{\circ} \mathrm{C}$ results in the increase of the sample purity. Further increase of the temperature causes the increase of the number of the defects in the graphitic structure of CNTs, and number of the amorphous species in the sample. Therefore, during the optimization of low temperature growth of CNTs one has to be aware that by lowering of the process temperature the sample quality drops. Additionally, the systematic study of this process is required in order to obtain the sample at the possible lowest temperature and the highest quality.

Second common technique to estimate the sample quality is TGA/DTA (the data not shown here). DTA curves were fitted to multipeaks Lorentzian distributions and 

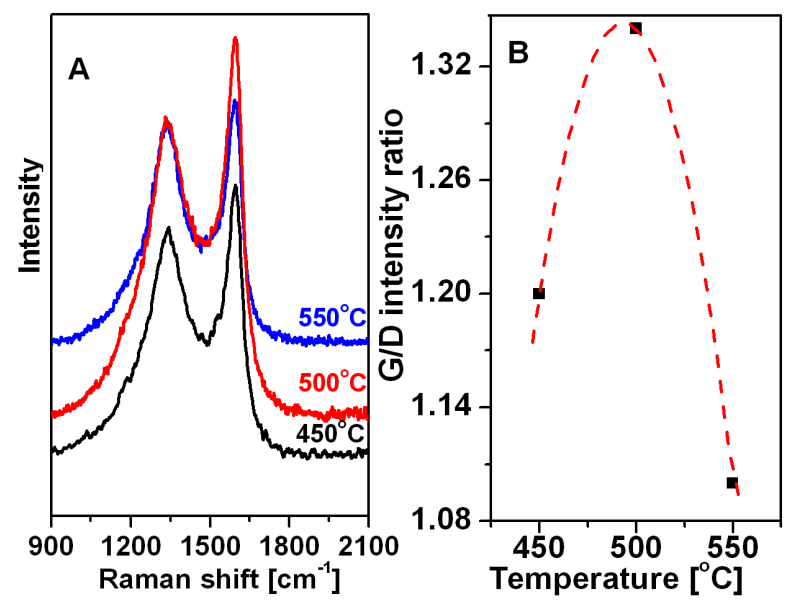

Fig. 4. (A) Raman spectra of the samples synthesized at the $450^{\circ} \mathrm{C}, 500^{\circ} \mathrm{C}$ and $550^{\circ} \mathrm{C}$ temperatures, (B) the intensities of $\mathrm{G} / \mathrm{D}$ ratios versus process temperature.

Table showed the results of the carbon fractions contained in each temperature. The highest concentration of the carbon nanotubes $(48.4 \%)$ in the experiment at $500^{\circ} \mathrm{C}$ in respect of the experiments at $450^{\circ} \mathrm{C}(41.1 \%)$ and $550^{\circ} \mathrm{C}(37.5 \%)$ was observed. Therefore, together with TEM observation and Raman spectroscopy results it is easy to conclude that the material prepared at the temperature of $500^{\circ} \mathrm{C}$ contains the highest abundance of the carbon nanotubes with the lowest number of the defects in the CNTs structure and the lowest content of the amorphous carbon in the bulk sample.

TABLE

Carbon fractions contained in each temperature.

\begin{tabular}{c|c|c|c}
\hline \hline Temperature & $\begin{array}{c}\text { Amorphous } \\
\text { carbon } \\
\text { [wt.\%] }\end{array}$ & $\begin{array}{c}\text { Carbon } \\
\text { nanotubes } \\
\text { [wt.\%] }\end{array}$ & $\begin{array}{c}\text { Graphitic } \\
\text { nanoparticles } \\
\text { [wt.\%] }\end{array}$ \\
\hline $450^{\circ} \mathrm{C}$ & 40.0 & 41.1 & 18.9 \\
$500^{\circ} \mathrm{C}$ & 30.0 & 48.4 & 21.6 \\
$550^{\circ} \mathrm{C}$ & 31.3 & 37.5 & 31.2
\end{tabular}

\section{Conclusions}

To summarize, we have presented a study on the formation of CNTs using low temperatures $\left(405^{\circ} \mathrm{C}, 450^{\circ} \mathrm{C}\right.$, $500^{\circ} \mathrm{C}$ and $550^{\circ} \mathrm{C}$ ) in the CVD processes. The temperature $405^{\circ} \mathrm{C}$ was too low to obtain CNTs. In the samples synthesized at $450^{\circ} \mathrm{C}, 500^{\circ} \mathrm{C}$ and $550^{\circ} \mathrm{C}$ abundance of nanotubes was observed. The increase (higher up $500^{\circ} \mathrm{C}$ ) of the temperature causes the increase of the number of the defects in the graphitic structure of CNTs, and number of the amorphous species in the samples.
The lowest temperature to activate the catalysts for nanotubes lies between $405^{\circ} \mathrm{C}$ and $450^{\circ} \mathrm{C}$. To get the exact temperature for the CNTs formation more experimental studies should be conducted.

The very important observation is the reduction of the carbon nanotubes diameter distribution by the factor of three for the sample produced at the temperature up to $550^{\circ} \mathrm{C}$ in respect of the sample produced at $850^{\circ} \mathrm{C}$.

\section{Acknowledgments}

This work was sponsored by the State Committee for Scientific Research grant 1 TO9B 00930 (E.B.-P.). The authors are grateful for financial support of EU commission within "Carbio" project on "Multifunctional carbon nanotubes for biomedical application" — Marie Curie Fellowship (EU).

\section{References}

[1] S. Iijima, Nature 354, 56 (1991).

[2] M.M.J. Treacy, T.W. Ebbesen, J.M. Gibson, Nature 381, 678 (1996).

[3] E.W. Wong, P.E. Sheehan, C.M. Lieber, Science 277 , 1971 (1997).

[4] S. Frank, P. Poncharal, Z.L. Wang, W.A. de Heer, Science 280, 1744 (1998).

[5] T.W. Ebbesen, P.M. Ajayan, Nature 358, 220 (1992).

[6] A. Thess, R. Lee, P. Nikolaev, H.J. Dai, P. Petit, J. Robert, Xu.Y.H. Lee, S.G. Kim, A.G. Rinzler, D.T. Colbert, G.E. Scuseria, D. Tomanek, J.E. Fischer, R.E. Smalley, Science 273, 483 (1996).

[7] M. Joseyacaman, M. Mikiyoshida, L. Rendon, J.G. Santiesteban, Appl. Phys. Lett. 62, 657 (1993).

[8] M. Endo, K. Takeuchi, K. Kobori, K. Takahashi, H.W. Kroto, Carbon 33, 873 (1995).

[9] Z.F. Ren, Z.P. Huang, J.W. Xu, J.H. Wang, P. Bush, M.P. Siegal, N. Provencio, Science 282, 1105 (1998).

[10] R. Andrews, D. Jacques, A.M. Rao, F. Derbyshire, D. Qian, X. Fan, E.C. Dickey, J. Chen, Chem. Phys. Lett. 303, 467 (1999).

[11] H.J. Dai, A.G. Rinzler, P. Nikolaev, A. Thess, D.T. Colbert, R.E. Smalley, Chem. Phys. Lett. 260, 471-475 (1996).

[12] S. Huang, L. Dai, A.W.H. Mau, Adv. Mater. 14, 1140 (2002).

[13] Y.S. Min, E.J. Bae, B.S. Oh, D. Kang, W. Park, J. Am. Chem. Soc. 127, 12498 (2005).

[14] L. Delzeit, I. MaAninch, B.A. Cruden, D. Hash, B. Chen, J. Han, M. Meyyappan, J. Appl. Phys. 91, 6027 (2002).

[15] J.I.B. Wilson, N. Scheerbaum, S. Karim, N. Polwart, P. John, Y. Fan, A.G. Fitzgerald, Diamond Relat. Mater. 11, 918 (2002).

[16] A. Bachmatiuk, E. Borowiak-Palen, M.H. Rümmeli, C. Kramberger, H.-W. Hübers, T. Gemming, T. Pichler, R.J. Kalenczuk, Nanotechnology 18, 275610 (2007). 